\title{
О вибродиагностике технически сложных промышленных объектов
}

\author{
А. Мирсков, с. н.с. ${ }^{1}$, С. Шиляев ${ }^{1}$
}

УДК 621.317| ВАК 05.11.16

\begin{abstract}
Необходимость обеспечения безаварийной работы технически сложных объектов (ТСО) привело к развитию новых производственных технологий диагностики и обслуживания ТСО. От планово-предупредительного технического обслуживания по назначенному ресурсу ТСО, применяемого в промышленности ранее, интенсивно переходят к эксплуатации и обслуживанию ТСО по фактическому состоянию. Применение спектральных методов вибродиагностики с оперативным поиском, точной локализацией, оценкой фактического состояния и прогнозированием развития износа кинематических узлов ТСО обеспечит повышение эксплуатационной безопасности и качества обслуживания ТСО.
\end{abstract}

истема планово-предупредительного ремонта (ППР) ТСО предполагает полную или частичную разборку оборудования с целью профилактического осмотра, технического обслуживания или капитального ремонта, независимо от его фактического технического состояния, через заранее определенные интервалы времени. Процедура ППР существенно уменьшает вероятность аварии, но не предохраняет механизм от неожиданных повреждений в межремонтный период, а переборки ТСО только ускоряют износ узлов. Кроме того, переборки могут вносить новые непредвиденные дефекты: перекосы осей, повышенные или заниженные зазоры, загрязнение и прочие технологические дефекты, сокращающие срок жизни ТСО, что требует проведения дополнительных ремонтных работ и, соответственно, дополнительных затрат.

Поэтому одной из первостепенных задач является переход от эксплуатации по заранее назначенному ресурсу к технологии эксплуатации и обслуживанию по

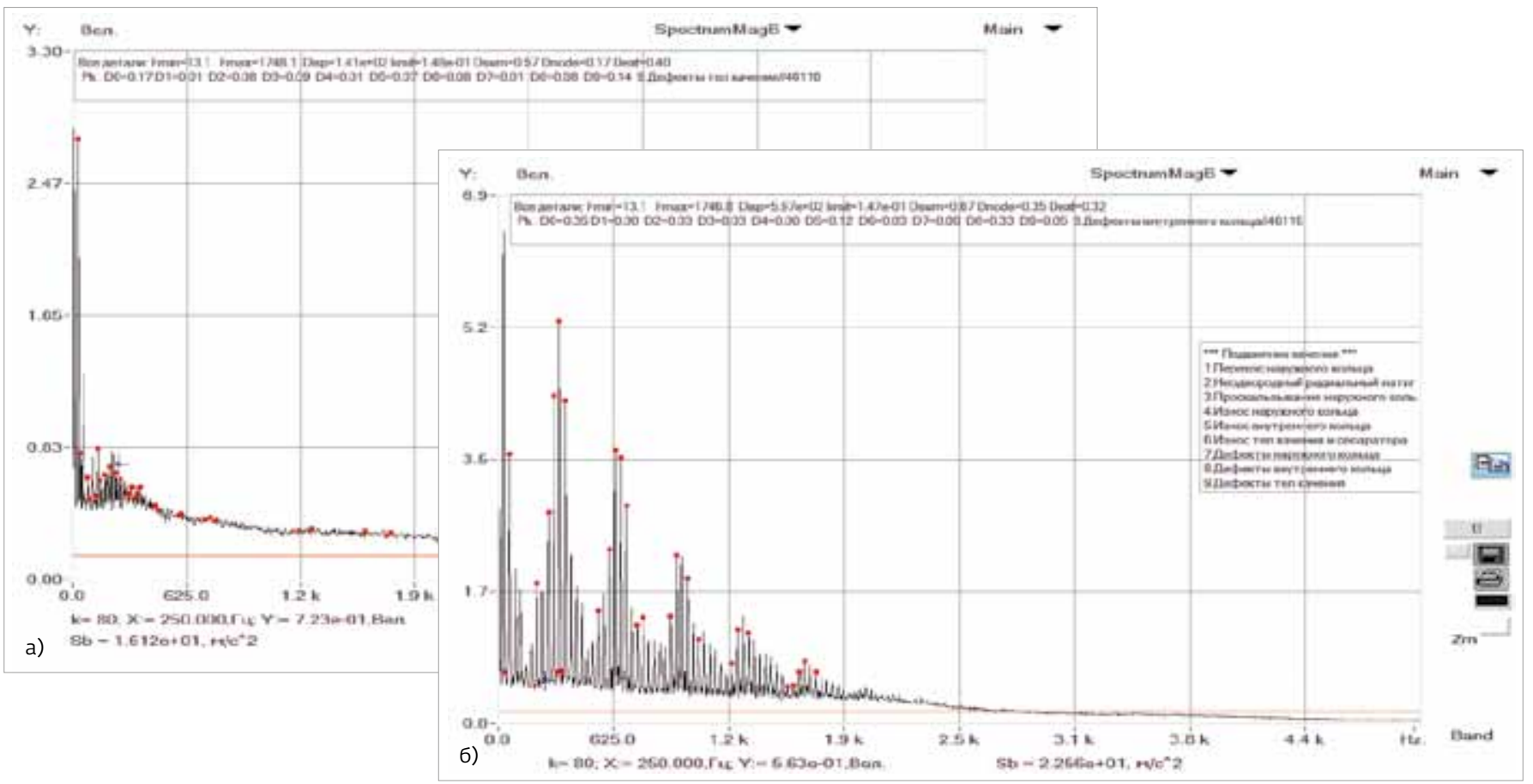

Рис. 1. Спектр огибающей вибраций подшипника 46116: а - без дефекта; 6 - дефект внутреннего кольца 
фактическому состоянию ТСО. Эта технология призвана устранить неожиданные поломки, обеспечить надежную работу механизмов и экономию средств за счет сокращения простоев и необоснованного демонтажа оборудования [1]. Современные технологии сбора, передачи и хранения данных позволят удаленно от ТСО осуществлять контроль технического состояния и своевременно обслуживать ТСО по состоянию [2].

Решение задач вибродиагностики ТСО предполагает изучение кинематической схемы объекта диагностики, выбор режима его работы и фиксированных мест установки измерительных датчиков, использование необходимого измерительного оборудования и информационной базы для описания технических характеристик объекта диагностики, хранения и обработки результатов виброакустического мониторинга [3-7].

Спектральные характеристики и распределение дефектов $D_{i}$ для подшипника типа 46116 (без дефекта и с дефектом внутреннего кольца) приведены на рис. 1. Измерения проводились на стенде обкатки подшипников (специальном вибродиагностическом станке Сп-180М). Уровень дефекта $D_{i}$ определялся согласно приведенному

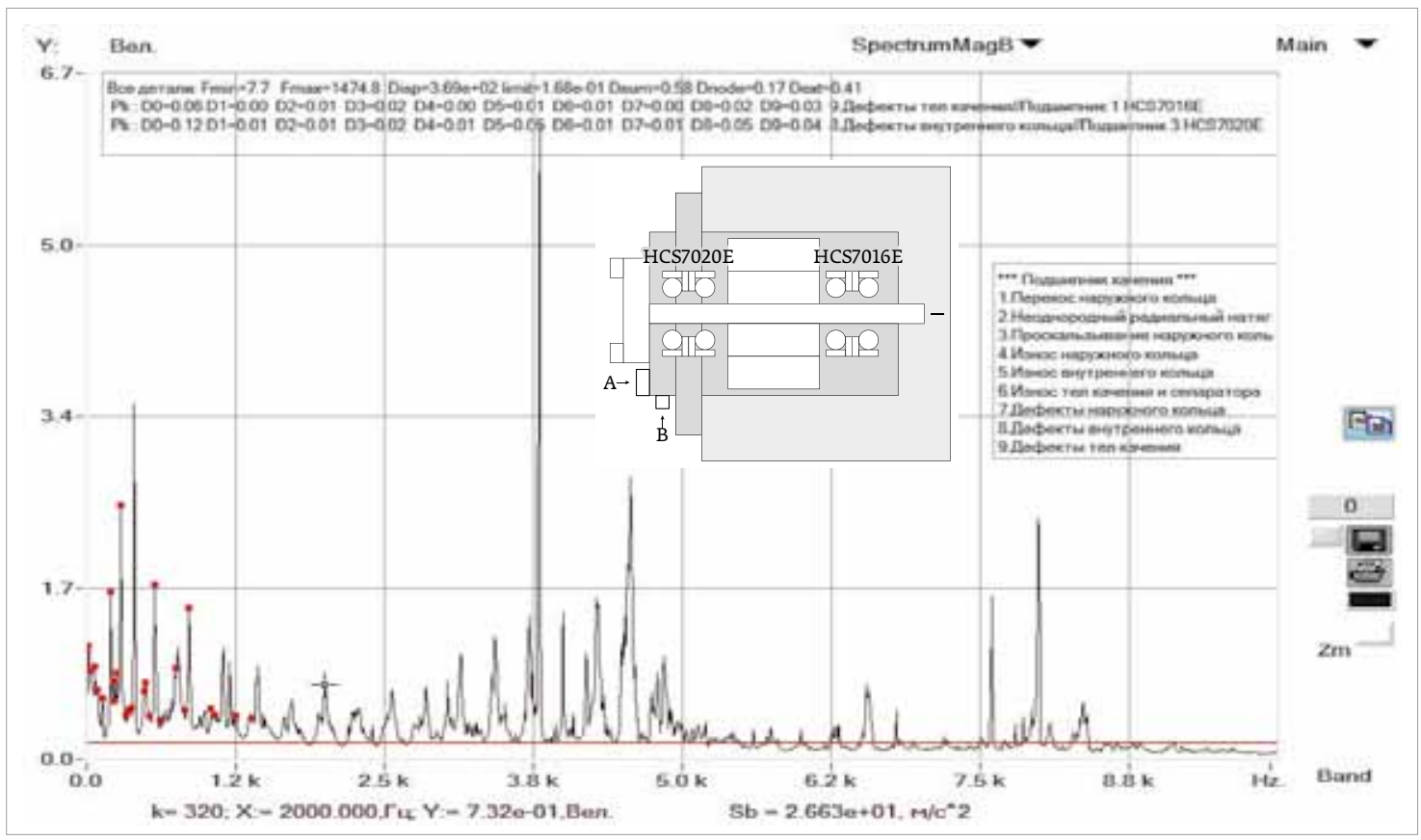

Рис. 2. Спектр огибающей вибраций подшипников шпиндельного узла

IBAG HF 260, частота оборотов вала шпинделя 1000 об/мин

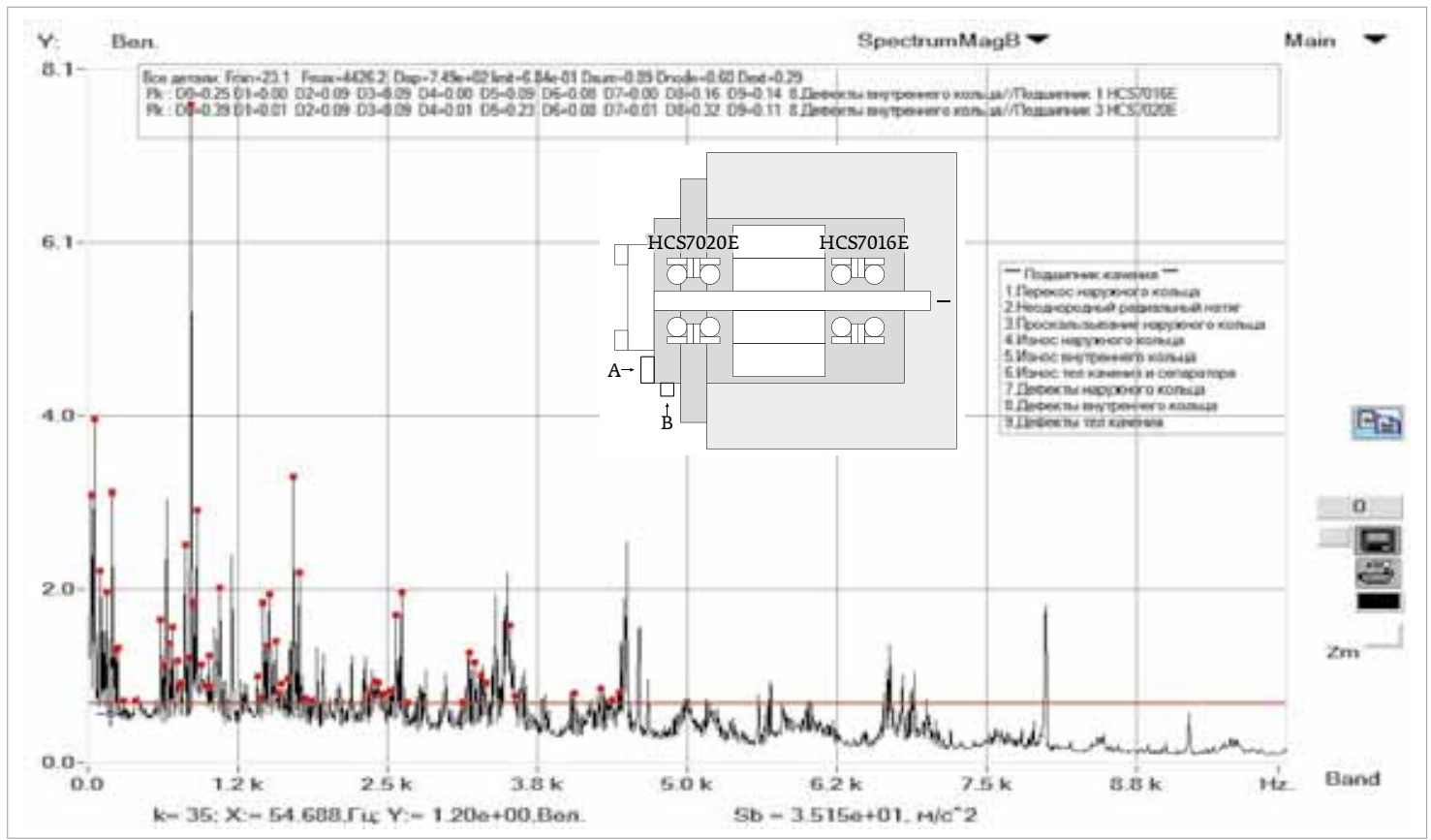

Рис. 3. Спектр огибающей вибраций подшипников шпиндельного узла IBAC HF 260, частота оборотов вала шпинделя 2000 об/мин 


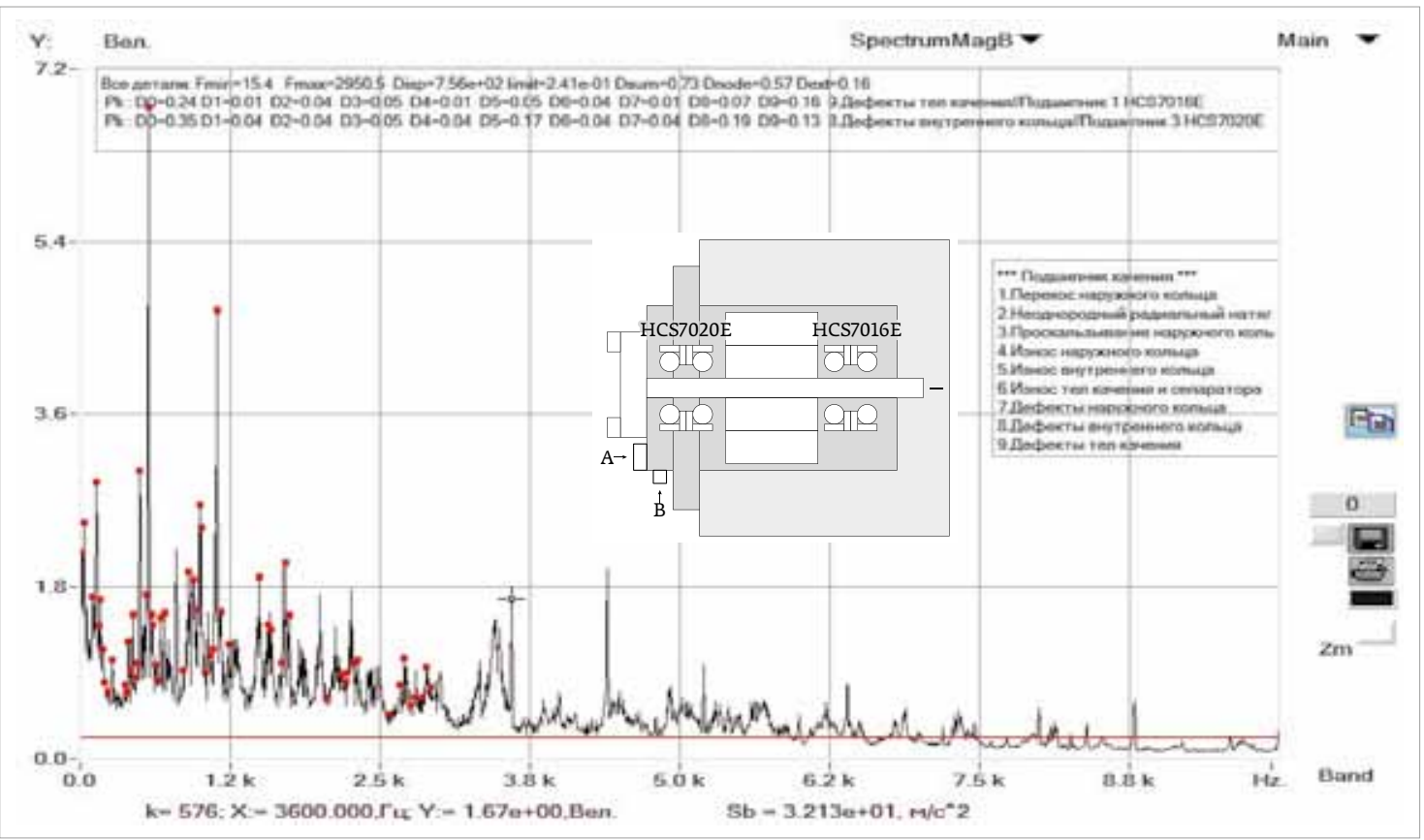

Рис. 4. Спектр
огибающей
вибраций
подшипников
шпиндельного
узла
IBAC HF 260,
частота
оборотов вала
шпинделя
3000 об / мин

ниже выражению наложением спектров-шаблонов дефектов [5] на расчетные спектры:

$$
D_{i}=\sigma_{i}^{2} / \sigma^{2}
$$

где: $\sigma^{2}=\sum_{k=0}^{N} \mathrm{G}_{k}^{2}-$ мощность (дисперсия) сигнала по спектру;

$$
\begin{aligned}
& \sigma_{i}^{2}=\sum_{j}^{m} \sum_{j-1}^{j+1} \mathrm{G}_{k}^{2}-\underset{\text { мощность спектральных составляю- }}{\text { щи го дефекта по спектру; }} \\
& D_{\text {node }}=D_{0}=\sum_{j=1}^{m} D_{i}-\begin{array}{c}
\text { суммарная мощность дефектов } \\
\text { кинематического узла. }
\end{array}
\end{aligned}
$$

Результаты диагностики мотор-шпинделя IBAG HF 260 перед проведением профилактического обслуживания до разборки приведены на рис. 2-4. Измерения проводились на холостом ходу при фиксированных числах оборотов вала шпинделя: 1000, 2000 и 3000 об/мин. Там же приведена кинематическая схема шпинделя и расположение измерительных вибродатчиков.

Анализ данных (см. рис. 2-4) показывает, что независимо от числа оборотов вала шпинделя прослеживается наибольший уровень дефектов для сдвоенных упорнорадиальных подшипников HCS7020Е передней опоры. Причем с ростом числа оборотов вала шпинделя растут дисперсия вибраций и уровни дефектов [8].

Поименованные дефекты подшипников свидетельствуют о том, что для наружного кольца $\left(D_{1}, D_{4}, D_{7}\right)$ они не обнаружены. Уровни дефектов внутреннего кольца $D_{5}, D_{8}$ и тел качения $D_{9}$ с ростом числа оборотов всегда присутствуют и перераспределяются между собой для подшипников как передней, так и задней опоры.
Разборка подшипников передней опоры шпинделя HCS7020Е подтвердила факт наличия дефектов внутреннего кольца, а именно бринеллирования, переднего подшипника опоры.

\section{Стремитесь к точности вместе с нами! ООО «Руднев-Шиляев" +7 495 787-63-67, +7 495 787-63-68, +7 495 787-63-69}

\section{ЛИТЕРАТУРА}

1. ГОСТ Р ИСО 13381-1-2011. Контроль состояния и диагностика машин. Прогнозирование технического состояния. Общее руководство.

2. ГОСТ Р ИСО 13374-3-2015. Контроль состояния и диагностика машин. Обработка, представление и передача данных. Передача данных.

3. Мирсков А., Шиляев С. Сертификация программного обеспечения высокотехнологичных промышленных изделий // ЭЛЕКТРОНИКА: Наука, Технология, Бизнес. 2020. № 2. с. 76-79.

4. http://www.rudshel.ru/show.php?dev=43.

5. Русов В.А. Диагностика дефектов вращающегося оборудования по вибрационным сигналам. - Пермь: ПФВ «ВиброЦентр", 2012г

6. ГОСТ Р ИСО 13372-2013. Контроль состояния и диагностика машин. Термины и определения.

7. ГОСт Р ИСО 13373-3-2016. Контроль состояния и диагностика машин. Вибрационный контроль состояния машин. Руководство по диагностированию по параметрам вибрации.

8. ГОСТ Р ИСО 13373-2-2009. Контроль состояния и диагностика машин. Вибрационный контроль состояния машин. Обработка, анализ и представление результатов измерений вибрации. 


\section{Осциллографы реального времени с полосой пропускания - 1 ГГц}

\section{серия АКИП-4134}

Полоса - шире! Скорость - выше!

Цены - ниже!
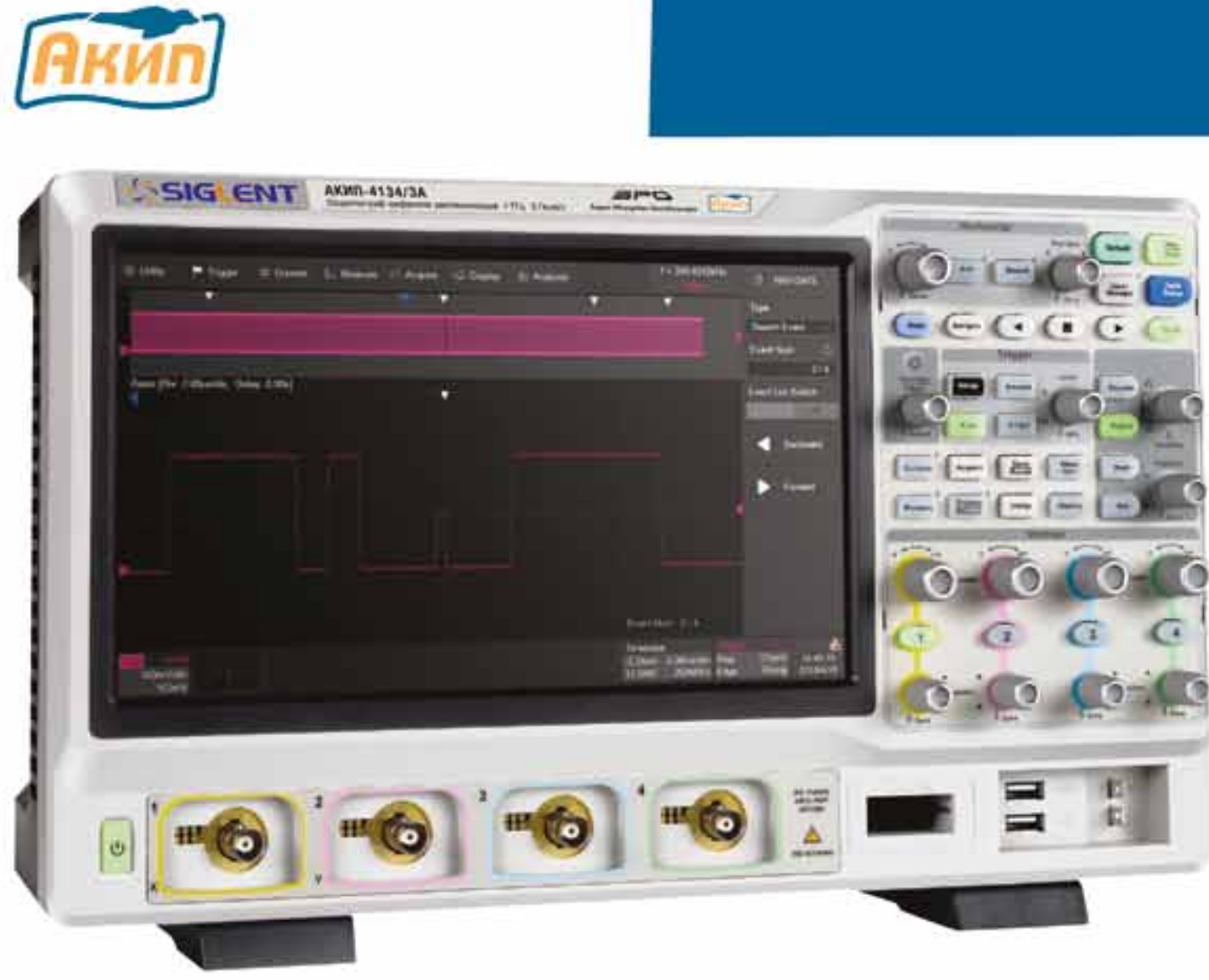

- Полоса пропускания 1 ТГЦ/ 500 МГц/ 350 МГц

- Частота дискретизации 5 Гвы6/с

- Память до 250 МБ

- Высокая скорость сбора данных: до 110.000 осц./сек

- Емкостной сенсорный экран с технологией Multi-touch

- Синхронизация и декодирование: I²C, SPI, UART/RS232, CAN, LIN

Опции:

- Синхронизация и декодирование: ${ }^{2} \mathrm{~S}$, MIL-1553, FlexRay

- Осциллограф смешанных сигналов 16 цифровых каналов

- Генератор сигналов (функциональный + СПФ):

частота дискретизации 125 Мвыб/с, диапазон до 25 МГц 